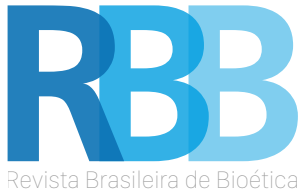

\section{O papel da bioética no enfrentamento do racismo}

The role of bioethics in coping with racism

Resumo: 0 objetivo deste artigo é apresentar reflexões sobre o racismo, trazê-lo para os dias atuais e pensar, por meio da bioética, formas de torná-lo visível, de compreendê-lo e de enfrentá-lo. Metodologicamente, foram apresentadas, inicialmente, reflexões sobre o racismo e a raça, a partir da perspectiva histórica levantada pelo autor camaronês Achille Mbembe; posteriormente, com base em revisão bibliográfica de artigos produzidos em universidades norte-americanas, travou-se discussão sobre a presença do racismo na agenda bioética e se estaria esta preparada para enfrentar a questão; por fim, abordou-se a posição da bioética latino-americana relativamente ao tema do racismo e sua preocupação com as questões sociais persistentes. Concluiu-se que a bioética deve, sim, enfatizar o debate sobre o tema do racismo, as operações de poder, hierarquização e seus impactos nos dias atuais, de modo a continuar atuando de forma verdadeiramente crítica no combate das inequidades.

Palavras-chave: bioética; racismo; raça; colonialidade; modernidade.

Abstract: The purpose of this article is to present reflections on racism, bring it to the present day and think, through bioethics, ways to make it visible, to understand it and to face it. Methodologically, reflections on racism and race were initially presented, based on the historical perspective raised by the Cameroonian author Achille Mbembe; after that and based on a bibliographical review of articles produced in North American universities, a discussion was held about the presence of racism in the bioethical agenda and whether it was prepared to face the issue; finally, the position of Latin American bioethics on the subject of racism and its preoccupation with persistent social issues was discussed. It was concluded that Bioethics must emphasize the debate on the theme of racism, power operations, hierarchization and its impacts in the present days, in order to continue acting in a truly critical way against inequities.

Keywords: bioethics; racism; race; coloniality; modernity. 
As notícias sobre mortes de negros pela polícia nos Estados Unidos têm sido uma constante nos veículos de comunicação. Ainda que algumas manchetes apontem sentimentos de indignação, providências efetivas não são tomadas e a violência permanece por um motivo que tem cor e nome: racismo. A violência contra negros, no entanto, não é exclusividade norte-americana. No Brasil assistimos, todos os dias, a cenas de discriminação, quer no que se refere a acesso a melhores postos de trabalho, a atendimento adequado de saúde, a ingresso em boas escolas.

Muitos poderiam dizer que não se trata de preconceito, que o racismo é coisa que ficou no passado e que nos tempos modernos o que se prega é a diversidade, a tolerância, a igualdade num mundo entrelaçado pela multiplicidade de raças. No entanto, o simples uso do termo raça, a necessidade de se falar em tolerância e de abrigo das diferenças traz à tona uma verdade histórica que o tempo apenas dissimulou: a raça é produto do racismo e esse racismo velado que impera nos dias de hoje é talvez mais violento e pernicioso que o racismo dos tempos de escravidão. Defende-se que no Brasil o problema é a pobreza e que todos somos mestiços. Na verdade, trata-se de um discurso para que façamos negações desse racismo, que continua sendo o lema de sustentação do Estado no processo de caminhada da modernidade. Com efeito, o surgimento da modernidade deu-se como uma forma de organização do poder, do saber e da essência humana, mediante a instalação de uma hierarquia entre grupos ou povos, estruturada de forma colonial e apta a controlar a política, as ciências e a própria vida (Nascimento, 2010).

O racismo, nos dias de hoje, apenas mudou de roupa, mas os protagonistas continuam os mesmos: de um lado, o negro subalterno; do outro, o Estado, com seu controle hierarquizado das populações; entre eles, uma sociedade educada para que esse controle funcione. Pela educação (quer na escola, na família ou na religião), forma-se uma imagem do negro como um ser inferior que a colonização veio salvar. cria-se o sentimento de que a raça branca teria causado um bem ao colonizar a raça negra, pois a estaria livrando da idiotia sendo misericordiosa para com sua inferioridade. Fecham-se os ol hos, desse modo, para os acontecimentos trágicos em relação ao negro e o gesto de ignorância e de indiferença da sociedade apaga nas consciências o dever e a responsabilidade.

Os discursos políticos exaltam a busca de meios de reparação histórica, de restituição e justiça. No entanto, as distâncias permanecem, a violência aumenta e indagações diversas continuam sem respostas. Como pensar a identidade de um povo negro diante da constatação de que essa imagem foi feita a partir do racismo? Quais os alcances das políticas de identidade? Como é possível a afirmação de uma identidade negra? Qual a natureza dessa diferença que se quer valorizar? Quem está reivindicando o lugar da diferença e da alteridade? O que significa a alteridade quando o modelo hegemônico é o outro? Como se devolve a alguém algo que a pessoa nunca teve? Como reconstruir um itinerário de direitos para que a igualdade possa ser uma ideia da modernidade? 
O objetivo deste artigo é apresentar reflexões sobre o racismo, trazê-lo para os dias atuais e pensar, por meio da bioética, formas de torná-lo visível, de compreendê-lo e de enfrentá-lo. O estudo toma como base as concepções de racismo e de raça propostas por Achille Mbembe, historiador, pensador pós-colonial e cientista político nascido em Camarões que, a partir da reconstrução histórica do racismo e da raça, destaca o crescimento das desigualdades no século XXI e alerta que os conflitos sociais, longe de alimentar apenas lutas de classe, acontecem, cada vez mais, em função do racismo, considerado em suas diversas dimensões. Após um trajeto histórico sobre a raça e o racismo, serão trazidas à tona, a partir de pesquisa de revisão bibliográfica, discussões travadas por pesquisadores de universidades norte-americanas sobre a presença do racismo na agenda bioética e se esta estaria preparada para enfrentar tal questão. Por fim, será abordada a posição da bioética desenvolvida na América Latina, sobretudo no Brasil, relativamente ao tema do racismo. Assim, passa-se à contextualização do que seja o racismo e a raça, para que, posteriormente, seja possível discuti-los a partir do ponto de vista da bioética.

\section{O racismo e a raça}

O negro surgiu sem direitos. Ele é uma construção histórica e em Mbembe podemos resgatar esse caminhar da raça e do racismo para melhor compreendermos como se dá nos dias de hoje a hierarquização social e como os benefícios econômicos e a utilização de recursos estratégicos se operam (ainda de forma violenta) contra as camadas da população mais vulnerabilizadas, marginalizadas e desprotegidas.

Mbembe (2014), a partir de um levantamento histórico que tem a experiência negra como pano central, propõe reflexões acerca do mundo atual e nos conclama a pensar a diferença e a vida, o semelhante e o dissemelhante, o excedente e o "em comum" (Mbembe, 2014, p. 21). Em sua obra 'Crítica da razão negra', al gumas indagações logo se apresentam: será que hoje estabelecemos uma relação diferente com o negro daquela do senhor e seus escravos? O próprio negro não se vê ainda apenas pela pele e na diferença? Conseguirá chegar ao conhecimento de si mesmo como um ser inteiro?

O pensamento europeu, desde os tempos da escravidão, aborda a identidade não como uma co-pertença a um mesmo mundo, pois enxerga o mundo por seu próprio espelho. Como consequência dessa autocontemplação, 'negro' e 'raça' têm significado a mesma coisa: designações primárias, pesadas e de repulsa. 0 corpo e o ser vivo são reduzidos a uma questão de aparência, de pele ou de cor (Mbembe, 2014).

O autor demarca o conjunto idealizador de raça e racismo a partir de três momentos: a espoliação organizada (transformação do homem em mercadoria); acesso à escrita (os negros começaram a articular uma linguagem para si e a reivindicar direitos); globalização dos mercados, privatização do mundo sob a égide do neoliberalismo, complexo militar pós-imperial e das tecnologias. No primeiro capitalismo, 
o nome 'negro' remetia à ideia de desapossamento da autodeterminação, do futuro e do tempo. Com o neoliberalismo, associou-se produção ao desejo, ou seja, conversão de tempo em dinheiro, valorização de mercado, racionalização do mundo por lógicas empresariais e, com isso, abertura de maior espaço à produção da indiferença e codificação da vida social em normas, categorias e números. Contemplase, assim, o surgimento de uma humanidade subalterna: "A este novo caráter descartável e solúvel, à sua institucionalização enquanto padrão de vida e à sua generalização ao mundo inteiro, chamamos o devir-negro do mundo" (Mbembe, 2014, p. 18).

Produto da máquina social e do capitalismo, negro significa exclusão, embrutecimento, degradação. Sua carne é vista como coisa e seu espírito, mercadoria. 0 nome negro sustenta, no entanto, um caráter de dualidade: é "veículo de instintos inferiores e de força caótica, ora como signo luminoso da possibilidade de redenção do mundo e da vida num dia de transfiguração" (Mbembe, 2014, p. 19). No ocaso do mundo euro-americano prega-se um racismo sem raça. O que se vê, no entanto, é que o agenciamento de poder não foi perdido, apenas aprimoraram-se as técnicas de ocultamento da discriminação. O alarde de que raça é algo conceitualmente impensável faz com que cultura e religião tomem o lugar da biologia, mas a ideia política de raça permanece, fazendo com que se proliferem categorias racializadas que alimentam todos os tipos de ódio e discriminação (Mbembe, 2014).

O trabalho do racismo consiste em encobri-lo com um véu, convertê-lo em algo diferente: é uma operação do imaginário e do inconsciente. "Para o racista, ver o negro é não ver que ele não está lá; que ele não existe; que ele mais não é do que o ponto de fixação patológico de uma ausência de relação" (Mbembe, 2014, p. 66). Constata-se, desse modo, que a lógica racista não está só ligada à luta de classes (fatores econômicos e sociais), mas à fobia, à baixeza e estupidez. É uma forma de covardia, de transferência para o outro, "no ódio, [d]o peso do horror inerente à nossa condição" (Mbembe, 2014, p. 72).

A raça tem estado na origem das catástrofes, crimes e carnificinas (Mbembe, 2014). O racismo, por sua vez, é um dos pilares da construção da modernidade e elemento de elaboração da chamada necropolítica, em que, a partir da construção de uma hierarquia populacional escalonada, algumas vidas passam a ter, politicamente, mais valor do que outras. A necropolítica estabelece uma relação radical e transgressora entre o Estado e a sociedade e, a partir dela, assiste-se à coisificação do ser humano, própria do capitalismo, e ao aniquilamento da integridade moral das populações. O ser humano passa a ser como uma peça de produção substituível, pois a acumulação de bens é o fim que prevalece (Mbembe, 2011).

O capitalismo do século XXI segue tanto a lógica de uma necropolítica, quanto a de um governo privado indireto, em que a ideia de soberania deriva da biopolítica foucaultiana dos séculos XIX e XX. Soberania, no caso, é o poder e capacidade de decidir quem vive e quem morre. Assim, impera uma cultura em que a violência é a 
norma e o Estado opera como uma instituição de gestão de controle legal das populações. Com efeito, não se pensa em população sem se pensar em noção de raça, em sentido negativo, como sistema de hierarquização, ou seja, não se trata de algo que faz parte da natureza, mas sim uma forma de se classificar as pessoas. É uma descrição que serve a um tipo de controle. Soberania significa, ainda, ocupação e ocupação significa relegar o excluído (colonizado) a uma terceira zona, localizada entre a condição de sujeito e de objeto (Mbembe, 2011).

O Estado, com a conivência da sociedade, propicia as condições para essa necropolítica, que permite o racismo, a xenofobia e todas as formas de exclusão e iniquidade. A morte civil é o primeiro passo de vinculação com a necropolítica e é difícil evitar essa morte civil se temos um Estado que nasceu racista. O Estado é armado (por meio da polícia) e o uso da força é o método das instituições (agenciadoras da violência usada, pretensamente, para garantir a paz e a ordem). Assim, permite-se que haja uma morte, uma violência para que o bom andamento do sistema se opere. A morte civil é um fenômeno da desumanização do negro, contemplada por um Estado que é racista, patriarcal e excludente.

O racismo do século XXI não é igual ao dos séculos precedentes. Novos desdobramentos se apresentam e os avanços tecnológicos estimulam a prática perigosa de controle das populações por vias diversas, inclusive técnicas genéticas que visam à eugenia. A globalização e seus efeitos trazem de volta o repúdio à raça e novas variantes de racismo se alastram baseadas no pensamento genômico que irrompe na consciência contemporânea. Mbembe (2014) ressalta que a fabricação de questões de raça se faz por todo lado e esse preconceito de cor se traduz nas instituições de segregação ("caso das leis <<Jim Crow〉> nos Estados Unidos e do regime do apartheid na África do Sul", p. 45) e na formação de grupos considerados inferiores. Migrantes são alvo de controle do ir e vir por tecnologias de reconhecimento diversas: estabelece-se uma indexação de categorias inteiras da população, as quais são depois submetidas a diversas formas de consignação racial. O migrante representa uma categoria essencialista da diferença, quer cultural, religiosa ou linguística. O novo século traz também à tona estudos sobre as distinções biológicas de grupos humanos, desencadeando explorações genômicas de doenças de certas esferas populacionais, quer por genealogia ou por delimitação geográfica, demarcando tipologias raciais. Verifica-se, ainda, que o mesmo ocorre nas técnicas e escolhas reprodutivas, "sob forma de seleção de embriões, e na linguagem da planificação da vida em geral" (Mbembe, 2014, p. 45). Num futuro não tão distante, não se pode garantir que essas armas biotecnológicas de seleção de embriões não sejam usadas no controle da qualidade das populações para eliminar raças tidas como indesejáveis.

Assim, a partir de tais perspectivas e levando-se em conta o compromisso da bioética com os vulneráveis, com a qualidade da vida humana, com temas de direitos humanos e cidadania, com a diversidade cultural, o racismo e diversas outras formas de discriminação, dentre outros, discutir-se-á, a seguir, o seu papel na visibilização e no enfrentamento do racismo. 


\section{A bioética e o racismo}

Apesar da discriminação ser considerada ilegal, existem vários fatores que contribuem para a sua prática: as escolas são ambientes de segregação familiar; um endereço tem impactos profundos nas condições econômicas, sociais e de saúde; a construção político-ideológica de opressão racial de certos grupos; estruturas sociais, leis e práticas que reforçam o racismo; falta de justiça social na base das instituições (Parsi, 2016). Dentre as situações de racismo mais comuns, destaca-se que os jovens negros são os alvos mais constantes da violência policial; que discriminações diversas ocorrem no sistema judiciário criminal, na forma de um maior número de prisão de afro-descendentes, exclusão dos negros de júri popular e existência de poucos advogados negros; a renda média dos negros é menor do que a de outros grupos em trabalhos idênticos; alta prevalência de pobreza entre os negros; crianças afro-descendentes mantêm uma taxa de baixo crescimento econômico; segregação das áreas de habitação e de acesso ao ensino (Danis, Wilson, White, 2016). Segundo estudos, todos esses determinantes sociais têm impacto negativo na saúde da população negra, que apresenta maior nível de estresse e de depressão, além de desenvolver maior taxa de doenças crônicas e apresentar menor expectativa de vida (Taylor, Turner, 2002).

Os problemas do racismo e da violência racial são complexos, multifatoriais e historicamente enraizados e alguns afirmam que, apesar de toda a carga moral que envolve a matéria, os bioeticistas não têm contribuído a contento para o enfrentamento do assunto, mesmo que a preocupação com a justiça social seja um dos maiores compromissos da bioética (Danis, Wilson, White, 2016). Para alguns, todo esse complexo ciclo de desvantagens sociais persistentes que assolam o negro está fora do campo de familiaridade da bioética. Outros, no entanto, defendem a existência de bases sólidas para se afirmar o contrário (Danis, Wilson, White, 2016).

De acordo com o estudo de Danis, Wilson e White (2016), os que acreditam que a bioética tem agido de forma insuficiente no enfrentamento do racismo e da violência racial apontam que isso ocorre em razão das seguintes dificuldades: existe parco conhecimento acerca dos trabalhos desenvolvidos por escritores especialistas na filosofia africana; há uma necessidade de se familiarizar melhor com as evidências empíricas acerca da pobreza, racismo e violência racial, bem como dos efeitos físicos e psicológicos infligidos pela discriminação de raça; existe pouca compreensão sobre os efeitos de longo prazo do racismo em relação a uma juventude marginalizada, desajustada e que é vítima constante da violência policial; necessidade de conscientização acerca de vieses raciais e comportamentos usualmente presentes dentro e fora do cenário dos sistemas de saúde; a postura de mediador neutro do bioeticista é incabível em situações de desequilíbrio de poder; pouca experiência, necessidade de treinamento e engajamento multidisciplinar. Por outro lado, aqueles que reconhecem a contribuição da bioética para as questões relacionadas ao racismo destacam o seguinte: os bioeticistas são eticamente treinados não só para lidar com questões que envolvem pesquisas ou práticas clínicas, mas também com injustiças sociais 
presentes nas políticas de acesso e distribuiç̧ão dos cuidados em saúde; geralmente, os dilemas éticos mais contundentes e que afetam a saúde e o bem-estar dos grupos mais vulneráveis da sociedade encontram-se fora do cenário dos cuidados em saúde, por isso a formação bioética não se limita a esse aspecto; os determinantes sociais da saúde, preocupação que consta da agenda bioética, contribuem igualmente ou até mais do que os cuidados médicos para a saúde e bem-estar de pacientes; ao se falar em determinantes sociais da saúde, não se pode perder de vista as consequências geradas pelo racismo.

Assim, para Danis, Wilson e White (2016), ainda que o racismo ocorra fora do cenário da saúde, a atuação da bioética é essencial para a discussão da violência racial e do racismo institucional. No entanto, para que atinjam suas finalidades, os autores ressaltam que as práticas bioéticas devem ser revistas, a começar pelos métodos de ensino. Segundo eles, se a justiça é uma das maiores preocupações da bioética, esse compromisso deve refletir na obrigação de promover equidade em saúde e iguais oportunidades, por isso, o ensino da bioética deve debater as injustiças sociais que afligem a população afrodescendente, procurando entender essas disparidades que surgem e são mantidas. A bioética pode contribuir, ainda, se inteirando sobre os trabalhos filosóficos de estudiosos da cultura africana, inclusive se familiarizando com as evidências empíricas relativas à pobreza, racismo e violência racial (o que deve ser transmitido aos alunos); combatendo os vieses raciais inconscientes que prevalecem nos ambientes de cuidados em saúde e que são perpetuados pela forma de educação médica; se engajando de forma mais ativa para obter mudanças comportamentais e institucionais; propiciando a presença de um número mais significativo de bioeticistas negros na Academia.

Para Stone (2012), os princípios de solidariedade e os cuidados devem estar atrelados ao respeito às pessoas e à justiça. A bioética, nesse ponto, pode e deve ser um parceiro atuante no que diz respeito ao racismo e à saúde, mediante a construção de uma rede de relações e a partir da aprendizagem com outras áreas, atravessando fronteiras e transformando as instituições, com humildade, persistência e paciência (Stone, 2016). Para enfrentar o racismo, os bioeticistas devem encarar sua 'brancura' e alargar seu papel primário de análise ética (compreensão) para um campo que envolva também ações e mudanças (Stone, 2016). 'Brancura', no caso, não se refere necessariamente ao tom de pele dos bioeticistas, mas se relaciona às normas culturais e ideológicas que determinam como a bioética deve ser praticada e quais princípios e contextos são considerados relevantes, ou seja, na formatação das estruturas algumas condutas são mais dominantes que outras, legitimadas pela alegada preocupação de não maleficência ou de segurança do paciente, mas nem sempre ligadas ao melhor interesse deste. Espera-se que a bioética seja um instrumento de empoderamento da parte mais fraca, mediante a educação das partes interessadas acerca das questões éticas envolvidas. Quando se falha no engajamento com questões morais diversas e contextos múltiplos, corre-se o risco de se inocular diferenças que contribuem para a manutenção de espaços de exclusão de minorias. É por meio de mudança cultural que a bioética pode ser parte da solução, e não do problema (Ho, 2016). 
De acordo com Sodeke (2016), algumas das habilidades da bioética podem ser usadas no enfrentamento do racismo e da violência racial, quais sejam: estudos e análises filosóficas; consultas éticas; ensino; políticas; habilidades investigativas para pesquisas empíricas; divulgação e treinamento. O autor acredita, no entanto, que, além disso, é preciso ter coragem moral para se aplicar as habilidades bioéticas na obtenção dos resultados desejados, mediante ações que transcendam o usual e o esperado. Um dos primeiros passos para se entender o racismo é nomeá-lo de forma contundente, ou seja, para que se discuta a posição do negro é preciso dizer o que o termo 'negro' significa, conforme o que ele realmente é, de modo que, ao ser compreendido, possa-se pensar em formas de eliminar os preconceitos e discriminações a ele atrelados. As ações dos bioeticistas devem, assim, refletir respostas morais duras às situações de racismo, a despeito das pressões e das resistências populares e das políticas de manutenção do status quo.

Segundo Kuczewski (2016), quando confrontada com injustiças e arbitrariedades, tais como os sistemas de apartheid, a bioética deve fazer o que estiver ao seu alcance, razão pela qual a autoeducação e a educação de seus pares deve ser uma prioridade para que os bioeticistas estejam aptos a ajudar. Não existe fórmula, mas algumas habilidades trazidas pelo estudo da bioética podem ser de grande valia, como as habilidades particulares em pesquisa. Para o autor, a bioética deve ser uma aliada das pessoas que sofrem injustiças, uma voz que contribui ao acesso de iguais oportunidades a todos.

O estudo apresentado por Karkazis, Mano e Edu (2016) se alinha à perspectiva de combate à necropolítica e ao sistema de governo privado indireto quando aponta que raça, racismo e violência racial fazem parte das operações de poder. Ressaltam que os incidentes de violência contra os negros são justificados pela supremacia branca, por meio de normas e instituições de poder, como forma de autodefesa, o que leva não só à perpetuação do racismo e da violência sancionada pelo Estado, mas permite que tal violência não seja vista como uma violência. Na verdade, o que se percebe não são interações inter-raciais tensas, mas a perpetuação de uma longa e duradoura luta pelo poder. Os autores afirmam que "[a]ddressing systemic racial disadvantages requires understanding that the maintenance and exercise of power relies on race, racism, and racist violence as embedded in our systems, frameworks, foundations, everyday practices, and methodologies, and how individuals and groups differently benefit from these" (Karkazis, Mamo, Edu, 2016, p. 25).

Assim, para que os bioeticistas possam se engajar em ações antirracistas devem compreender primeiramente as nuances por meio das quais raça e racismo ensejam a continuidade de reprodução do poder. O próprio campo da bioética, por meio de suas práticas e das instituições a que se vincula, perpetua inequidades, pois suas estruturas de financiamento elegem as pesquisas que entendem prioritárias (e questões relativas à justiça racial não se enquadram dentre elas) e determinam a formação do conhecimento científico. Desde os tempos de escravidão até o colonialismo, o povo negro tem sido colocado fora da categoria de ser humano e isso 
persiste até os dias de hoje. A bioética precisa ser crítica e reconhecer o perigo de reproduzir categorias raciais, por não entender ou por ignorar as maneiras pelas quais tais categorias são construídas nas relações de poder, especialmente no que diz respeito à dominação racial (Karkazis, Mamo, Edu, 2016).

A bioética deve adotar uma abordagem interseccional no estudo e enfrentamento das complexas iniquidades, além de focar na questão da raça. A interseccionalidade estabelece correlação entre inequidades sistemáticas que criam e sustentam disparidades e põe em primeiro plano ativismo e transformação social como elementos que devem ser priorizados pela academia no sentido de se buscar justiça social para grupos vulneráveis e marginalizados (Grzanka, Brian, Shim, 2016).

Toda essa discussão recentemente entabulada por autores norte-americanos sobre a necessidade de ampliação da agenda bioética para questões que vão além dos conflitos morais presentes na pesquisa e nas práticas clínicas, de modo a abarcar contextos sociais outros que influenciam a saúde e o bem-estar de populações desfavorecidas, já vem ocorrendo na América-Latina há algum tempo. O problema é que a colonialidade do saber/poder que ainda persiste no século XXI tem o condão de, não raras vezes, abafar as vozes dos países periféricos frente aos interesses dos países centrais.

No Brasil, existem trabalhos que demonstram que a bioética e os estudos sobre a colonialidade são campos que se cruzam e que o diálogo entre eles reforça o escopo crítico da bioética, amplia seus fundamentos conceituais e contribui para sua maior politização (Nascimento, 2010). A bioética de Intervenção, por exemplo, é uma importante "ferramenta de denúncia, reflexão e busca de alternativas para a solução de problemas (bio)éticos que aparecem em um contexto típico das desigualdades registradas no Hemisfério Sul do mundo, especialmente na América-Latina, sobretudo os macroproblemas" (Nascimento, 2010, p. 57). Suas bases apoiam-se na luta contra o imperialismo moral e contra as situações persistentes de injustiças e iniquidades sociais (exclusão social, discriminação, violência, pobreza, acesso à saúde etc), sem perder de vista também as situações emergentes (avanços tecnológicos diversos), as quais são analisadas a partir da justiça social e voltada ao combate das desigualdades impostas pelo colonialismo e imperialismo (Garrafa e Porto apud Nascimento, 2010). A politização das questões morais ligadas ao racismo, nos moldes pregados pela bioética de Intervenção, ajuda a trazer à tona o invisível, o excluído, o marginalizado, o vulnerável, o oprimido e dá voz a uma população sem identidade, vítima das hierarquias de poder. "Uma perspectiva bioética é um modo de olhar o mundo da vida, seus conflitos e de pensar em soluções e alternativas a eles" (Nascimento, 2010, p. 58). A bioética é, de fato, um instrumento importante de combate ao racismo, em razão de seu potencial como instrumento de descolonização, a partir de discussões com movimentos sociais, por isso, é preciso fortalecê-la (Nascimento, 2010). 
Com efeito, não eliminamos o racismo, por isso é preciso continuar a luta em busca da celebração da alteridade, da abertura e da partilha, a partir de uma crítica política e ética do racismo. É necessário repartir o peso da história, trabalhar contra o passado, para que um futuro comum possa se abrir a todos. A reparação deve deixar de ser mobilizada apenas pelas vítimas da história, ou seja, deve-se, de um lado, abandonar o papel de vítima, mas de outro lado, deve-se impulsionar o opressor a assumir responsabilidades, articulando-se, assim, uma nova ética e uma nova política, voltadas à justiça (Mbembe, 2014). Assim, o primeiro passo para a igualdade social é reconhecer que o negro é "[s]implesmente um homem entre outros homens" (Fanon apud Mbembe, 2014, p. 297).

\section{Considerações finais}

Este artigo procurou trazer reflexões sobre a importância da bioética na discussão de questões relacionadas às práticas racistas ainda presentes em nossos dias. Demonstrou-se que a bioética dos países norte-americanos - que só agora parecem querer despertar para as consequências da colonialidade, para a necessidade de se combater o racismo e se proteger a diversidade cultural - ainda tem como preocupações centrais a pesquisa, as questões biomédicas e os avanços tecnológicos relacionados à saúde. A América-latina, por sua vez, apresenta uma bioética muito mais ampla, voltada não só às questões relacionadas à pesquisa e à saúde, mas também preocupada com a justiça social, a promoção da equidade em saúde e a garantia de iguais oportunidades a todos. Daí sua luta contra o imperialismo moral e sua busca constante pela reparação das situações persistentes de injustiça e iniquidades sociais.

Com efeito, a bioética, enquanto ética concreta preocupada também com as questões sociais persistentes, deve enfatizar o debate sobre o tema do racismo, sua história, as operações de poder e hierarquização, e seus impactos nos dias atuais, de modo que possa atuar de forma verdadeiramente crítica no combate das inequidades. Embora, de fato, muito ainda se tenha a fazer para se atingir uma bioética global, voltada a questões de interesse de todo o mundo, é possível sentir um avanço no sentido de se uniformizar sua linguagem e de se respeitar a diversidade cultural, e esse avanço tem sido conseguido sobretudo com o ativismo dos países do Sul.

Assim, além da importância da familiarização com a filosofia africana, da eliminação dos vieses raciais que persistem nos sistemas de saúde, do engajamento ativo para obtenção de mudanças comportamentais e institucionais, da diversidade cultural na academia e do ativismo voltado a ações e mudanças, conforme defendido na literatura, a bioética deve estar, ainda, sempre atenta à busca de políticas capazes de garantir a plena igualdade das pessoas, num contexto de diferenças. 


\section{Referências}

1. Danis $\mathbf{M}$, Wilson $\mathbf{Y}$, White $\mathbf{A}$. Bioethicists can and should contribute to addressing racism. The American Journal of Bioethics 2016; 16(4): 3-12.

2. Grzanka PR, Brian JD, Shim JK. My bioethics will be intersectional or it will be [bleep]. The American Journal of Bioethics 2016; 16(4): 27-29.

3. Ho A. Racism and bioethics: are we part of the problem? The American Journal of Bioethics 2016; 16(4): 23-24.

4. Karkazis K, Mamo L, Edu U. Keeping an eye on power in maintaining racial oppression and race-based violence. The American Journal of Bioethics 2016; 16(4): 25-27.

5. Kuczewski M. The really new Jim Crow: why bioethicists must ally with undocumented immigrants. The American Journal of Bioethics 2016; 16(4): 21-22.

6. Mbembe A. Necropolítica. Madrid: Mesulina, 2011.

7. Mbembe A. Crítica da razão negra. Portugal: Antígona, 2014.

8. Nascimento WF. Por uma vida descolonizada: diálogos entre a bioética de intervenção e os estudos sobre a colonialidade (tese). Brasília: Universidade de Brasília; 2010.

9. Parsi K. The unbearable whiteness of bioethics: exhorting bioethicists do address racism. The American Journal of Bioethics 2016; 16(4): 1-26.

10. Sodeke S. Bioethics skill sets can work, but it would take moral courage to apply them and get desired results. The American Journal of Bioethics 2016; 16(4): 19-20.

11. Stone J. Elderly \& older racial/ethnic minority healthcare inequalities: care, solidarity, and action. Cambridge Quaterly of Healthcare Ethics 2012; 21: 342-52.

12. Stone J. Racism and bioethics: experiences and reflections. The American Journal of Bioethics 2016; 16(4): 13-35.

13. Taylor J, Turner RJ. Perceived discrimination, social stress, and depression in the transi- tion to adulthood: racial contrasts. Social Psychology Quaterly 2002; 65(3): 213-25.

Recebido em: 22/08/2016. Aprovado em: 10/11/2016. 